\title{
The effect of food deprivation and expectancy on heart rate
}

ROBERT BUCKHOUT AHD TERRENCE GRACE WASHINGTON UNIVERSITY
Ss fasted for $24 \mathrm{hr}$. after being on a controlled diet. Group A expected to fast for $24 \mathrm{hr}$. and had HR measured with food cues present. Group B expected to fast for $36 \mathrm{hr}$. and were tested without food cues. At the $24 \mathrm{hr}$. mark, Group A showed significantly higher heart rate. It was concluded that significant HR arousal occurs in deprived human beings anticipating immediate satiation.

In 1959, Malmo postulated that physiological excitation could occur as a result of food and water deprivation. In support of his hypothesis, Malmo cited Belanger \& Feldman (1962) where rats were serially deprived of water for up to $72 \mathrm{hr}$. A monotonic relationship between deprivation and heart rate was observed when HR measurement was taken while the animal was in the presence of the drinking apparatus. Campbell \& Sheffield (1953) found that in the presence of environmental stimulation, food deprived rats were more active than satiated ones.

Asdourian \& Rimbey (1965) recorded the heart rate of seven adults at deprivation levels varying between 30 and $35 \mathrm{hr}$. They found no difference between HR measured after deprivation and HR measured on control days. The first author was an $S$ and the other six Ss were graduate students familiar with the purpose of the study, thus introducing the possibility of experimenter bias or at least uncontrolled expectancy.

The present study compared the heart rate of a group that expected to be deprived for $24 \mathrm{hr}$. and that of a group which expected to be deprived for $36 \mathrm{hr}$. In the case of the $24 \mathrm{hr}$. group, food was present at the time of recording the HR. It was predicted that the $24 \mathrm{hr}$. expectancy with food stimuli present would show higher activation than the $36 \mathrm{hr}$. expectancy in which there were no food cues present during the HR recording after $24 \mathrm{hr}$. actual deprivation.

Method

Subjects. Twenty male undergraduates, ages 18 to 22 years, served as Ss in two groups of 10 Ss matched for baseline HR.

Apparatus. Ss sat on a reclining chair, wearing earphones which carried the sound of a white noise generator at a constant intensity. Redux electrode paste was applied to the underside of the wrist and 1 in. $x 2$ in. spring clamp electrodes were attached. HR was recorded on a Grass Model 5C polygraph.

Ss filled out a daily mood scale which asked him to rate his feelings on a series of seven point adjective scales such as hungry-not hungry, etc. After HR had been taken the first time, each $\mathrm{S}$ filled out the medical inventory and was given instructions.
Design. Group A ate a controlled diet followed by a $24 \mathrm{hr}$. fasting period, and HR recording with food cues present. Group B ate a controlled diet, expected to fast for $36 \mathrm{hr}$. and had HR measured after $24 \mathrm{hr}$. with food cues absent.

Procedure. Ss came in for four recording sessions at which time HR was recorded for $14 \mathrm{~min}$. The controlled diet began at noon on the day of the first recording session. Ss ate lunch, did not eatuntil supper when they ate two packages of Instant Breakfast (580 calories). At breakfast they ate one package of Instant Breakfast (290 calories).

On the second day, Ss returned to have HR taken. They did not eat or drink anything that day except water. After $24 \mathrm{hr}$. deprivation, all Ss returned to have HR recorded. Group A knew that they could eat the food (Hershey bars, milk, etc.) that was placed in front of them, after the recording session. Group B expected to fast for several more hours and found no food stimuli present. Ss returned on the fourth day for final HR measurement.

\section{Results}

Changes in HR. Mean HR for the two groups was evaluated using the $t$ test. Only on day three-following the $24 \mathrm{hr}$. deprivation period-was there a significant difference between the two groups ( $p<.025$, one-tailed). The HR for the $24 \mathrm{hr}$. deprivation expectancy group was 9.8 beats per min. faster than the HR for the $36 \mathrm{hr}$. deprivation expectancy group after an actual deprivation period of $24 \mathrm{hr}$. for both (see Table 1).

While both groups showed a mean increase in $\mathrm{HR}$ after $24 \mathrm{hr}$. application of the Wilcoxon Matched-Pairs Signed-Ranks test to the data showed that the $24 \mathrm{hr}$. expectancy group had a significant increase in HR of 11.6 beats per min. following deprivation $(p<.01)$.

Subjective Ratings. It was found that on the hunger rating item, Group A (24 hr. expectancy), changed significantly $(p<.01), T=0$ (Wilcoxon Test) toward being more hungry following deprivation. Group B showed a non-significant change following deprivation. No between-group differences were found in any comparison of mood ratings.

Table 1. The heart rate means and standard deviations for the 24 hr. and $36 \mathrm{hr}$. expectancy groups for each of the four days of testing

\begin{tabular}{ccccccccc} 
& \multicolumn{1}{c}{ Day 1 } & \multicolumn{2}{c}{ Day 2 } & \multicolumn{2}{c}{ Day 3 } & \multicolumn{2}{c}{ Day 4 } \\
\hline & $M$ & SD & $M$ & SD & $M$ & SD & $M$ & SD \\
$24 \mathrm{hr}$. & 72.8 & 10.06 & 67.1 & 6.16 & 78.7 & 8.37 & 71.7 & 4.29 \\
$36 \mathrm{hr}$. & 71.3 & 10.60 & 64.1 & 7.22 & 68.9 & 10.53 & 67.5 & 9.15 \\
\hline
\end{tabular}




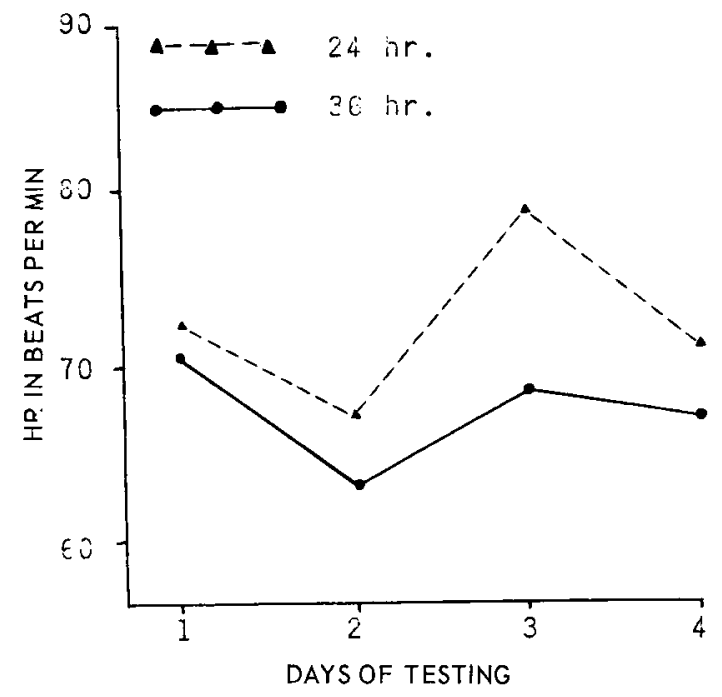

Fig. 1. The heart rate means for the $24 \mathrm{hr}$. expectancy group and the 36 hr. expectancy group for each of the four days of testing.

Interaction. Spearman's rank correlation was computed between the hunger ratings and HR observed before and after deprivation. While the correlations were not significantly greater than zero, it is important to note that the correlation for the $\mathbf{2 4} \mathrm{hr}$. expectancy group after deprivation was .50 as opposed to -.07 for the $36 \mathrm{hr}$. expectancy group. A test of significance of the difference between these two correlations yielded a significant $\mathrm{D} / \mathrm{S}_{\mathrm{zr}_{\mathbf{r}}{ }_{\mathrm{z}}}=3.78$; $(\mathrm{p}<.01)$, (DuBois, 1965).

Discussion

The results confirmed the prediction that the $24 \mathrm{hr}$. expectancy-food cues present condition would produce more HR activation than a $36 \mathrm{hr}$.-food cues absent condition. Activation was measured as $\mathrm{HR}$ increment over the previous control reading, following the $24 \mathrm{hr}$. period of food deprivation. While both groups showed an increase in HR following deprivation, only Ss in the 24-hr. food cues present condition showed a significant increase in HR. Present studies in our laboratory indicate that the mean HR of Ss tested without food deprivation show no significant inter-day changes.

These results generally support Malmo's 1959 con- tention that two factors are needed for activation: (1) the internal conditions produced by a state of physiological deprivation and (2) environmental stimulating conditions at the time of testing-conditions met in the present study by deprivation and the presence of food stimuli.

In this preliminary study, there was, in fact, a confounding of the $S$ "deprivation expectancy" and "stimulus present" variables. The two conditions were chosen and designed to maximize the S's expectancy of immediate need reduction in the one condition while minimizing it in the other. If expectancy can be thought of as a unitary variable, influenced by both instructional set (the projected length of deprivation) and relevant environmental cues (food stimuli), then the present results, both cognitive and physiological, suggest that the Ss facing a longer time until need reduction ( $36 \mathrm{hr}$. expectancy) may attenuate their evaluation of hunger and possibly their physiological manifestations of hunger as well.

It became clear to us that the S's "plan"-to use Miller, Galanter, \& Pribram's (1960) term-is an important consideration in predicting how a person will manage his physiological resources given a situation which will affect homeostatic functions.

It is tentatively concluded that HR arousal occurs in food deprived humans anticipating immediate satiation, while those who expect to continue deprivation show less HR arousal. These results are generally consistent with Malmo's activation theory.

\section{References}

Asdourian, D., \& Rimbay, M. Heart rate and deprivation in humans. Psychon. Sci., 1965, 3, 251-352.

Belanger, D., \& Feldman, S. Effects of water deprivation upon heart rate and instrumental activity in the rat. J. comp. physiol. Psychol., 1962, 55, 220-225.

Campbell, D. A., \& Sheffield, F. D. Relations of random activity to food deprivation. J. comp. physiol. Psychol., 1953, 46, 320322.

DuBois, P. An introduction to psychological statistics. New York: Harper \& Row, 1965, p. 349.

Malmo, R. Activation: a neuropsychological dimensions. Psychol. Rev., 1959, 66, 367-386.

Miller, G. A., Galanter, E., \& Pribram, K. H. Plans and the structure of behavior. New York: Henry Holt, 1960. 